\title{
Sodium bicarbonate causes dose-dependent increases in cerebral blood flow in infants and children with single-ventricle physiology
}

\author{
Erin M. Buckley ${ }^{1,2}$, Maryam Y. Naim³ ${ }^{3}$ Jennifer M. Lynch², Donna A. Goff ${ }^{4,5}$, Peter J. Schwab ${ }^{1}$, Laura K. Diaz ${ }^{6}$, Susan C. Nicolson 6 , \\ Lisa M. Montenegro ${ }^{6}$, Natasha A. Lavin7 ${ }^{7}$ Turgut Durduran ${ }^{2,8}$, Thomas L. Spray ${ }^{9}$, J. William Gaynor ${ }^{9}$, Mary E. Putt ${ }^{10}$, A. G. Yodh², \\ Mark A. Fogel ${ }^{4,11}$ and Daniel J. Licht ${ }^{1}$
}

\begin{abstract}
BACKGROUND: Sodium bicarbonate $\left(\mathrm{NaHCO}_{3}\right)$ is a common treatment for metabolic acidemia; however, little definitive information exists regarding its treatment efficacy and cerebral hemodynamic effects. This pilot observational study quantifies relative changes in cerebral blood flow $(\triangle \mathrm{rCBF})$ and oxyand deoxyhemoglobin concentrations $\left(\Delta \mathrm{HbO}_{2}\right.$ and $\left.\Delta \mathrm{Hb}\right)$ due to bolus administration of $\mathrm{NaHCO}_{3}$ in patients with mild base deficits.
\end{abstract}

METHODS: Infants and children with hypoplastic left heart syndrome (HLHS) were enrolled before cardiac surgery. $\mathrm{NaHCO}_{3}$ was given as needed for treatment of base deficit. Diffuse optical spectroscopies were used for $15 \mathrm{~min}$ postinjection to noninvasively monitor $\triangle \mathrm{Hb}, \Delta \mathrm{HbO}_{2}$, and $\triangle \mathrm{rCBF}$ relative to baseline before $\mathrm{NaHCO}_{3}$ administration.

RESULTS: Twenty-two anesthetized and mechanically ventilated patients with HLHS (aged $1 \mathrm{~d}$ to $4 \mathrm{y}$ ) received a median (interquartile range) dose of $1.1(0.8,1.8) \mathrm{mEq} / \mathrm{kg} \mathrm{NaHCO}$ administered intravenously over $10-20 \mathrm{~s}$ to treat a median (interquartile range) base deficit of $-4(-6,-3) \mathrm{mEq} / \mathrm{I}$. $\mathrm{NaHCO}_{3}$ caused significant dose-dependent increases in $\triangle \mathrm{rCBF}$; however, population-averaged $\triangle \mathrm{Hb}$ and $\triangle \mathrm{HbO}_{2}$ as compared with those of controls were not significant.

CONCLUSIONS: Dose-dependent increases in cerebral blood flow (CBF) caused by bolus administration of $\mathrm{NaHCO}_{3}$ are an important consideration in vulnerable populations wherein risk of rapid CBF fluctuations does not outweigh the benefit of treating a base deficit.

S odium bicarbonate $\left(\mathrm{NaHCO}_{3}\right)$ is a commonly used medication to treat metabolic acidemia from a variety of causes. Intravenous $\mathrm{NaHCO}_{3}$ acts by neutralizing excess acid in the blood to yield carbonic acid, which then dissociates into carbon dioxide and water, restoring physiologic $\mathrm{pH}$. The efficacy of $\mathrm{NaHCO}_{3}$ treatment for mild-to-moderate acidemia, however, is widely debated, and controversy exists over whether any true benefit results from the therapy (1-4). In fact, some data suggest that $\mathrm{NaHCO}_{3}$ may be harmful in certain populations. In preterm infants, for example, the use of $\mathrm{NaHCO}_{3}$ has been linked to intraventricular hemorrhage, hypernatremia, and death (2,5,6). Nevertheless, treatment of metabolic acidemia with $\mathrm{NaHCO}_{3}$ remains a common practice in many pediatric intensive care units and operating rooms.

Further understanding of the cerebral hemodynamic effects of rapid administration of $\mathrm{NaHCO}_{3}$ may illuminate the link between $\mathrm{NaHCO}_{3}$ and brain injury. It is known that administration of $\mathrm{NaHCO}_{3}$ causes an immediate and transient increase in the production of nonmetabolic $\mathrm{CO}_{2}(7-10)$, as well as a slight increase in plasma $\mathrm{pH}(7,11)$ and serum osmolality $(12,13)$. This increase in serum osmolality leads to a flow of intracellular water into the extracellular space to restore osmotic equilibrium and to an increase in arterial hemoglobin concentration and a decrease in hematocrit $(9,10,12,13)$. However, little definitive and quantitative information exists regarding the effects of $\mathrm{NaHCO}_{3}$ on cerebral hemodynamics.

Several publications on the effects of $\mathrm{NaHCO}_{3}$ on cerebral blood flow (CBF) report conflicting observations $(7,11,14-19)$. Lou et al. (17) observed substantial decreases in CBF measured by the Xe-133 clearance technique 5 min after $\mathrm{NaHCO}_{3}$ administration in seven newborn infants with respiratory distress. By contrast, Nakashima et al. (9) reported significant increases in $\mathrm{CBF}$ in five healthy adult volunteers after $\mathrm{NaHCO}_{3}$ administration. Finally, in a study of six neonatal dogs, Young et al. (19) observed no changes in $\mathrm{CBF}$ (measured with radioactive tracers) $30 \mathrm{~min}$ after $\mathrm{NaHCO}_{3}$ injection. These conflicting results may reflect the wide variety of experimental subjects studied (both humans and animals), the severity and cause of the acidemia, the dosage and rapidity of injection of $\mathrm{NaHCO}_{3}$, the use of mechanical ventilation, the anesthetic state, the method of

'Division of Neurology, The Children's Hospital of Philadelphia, Philadelphia, Pennsylvania; ${ }^{2}$ Department of Physics and Astronomy, University of Pennsylvania, Philadelphia, Pennsylvania; ${ }^{3}$ Division of Critical Care Medicine, The Children's Hospital of Philadelphia, Philadelphia, Pennsylvania; ${ }^{4}$ Division of Cardiology, The Children's Hospital of Philadelphia, Philadelphia, Pennsylvania; ${ }^{5}$ Division of Pediatric Cardiology, Loma Linda University Children's Hospital, Loma Linda, California; ${ }^{6}$ Division of Cardiothoracic Anesthesia, The Children's Hospital of Philadelphia, Philadelphia, Pennsylvania; ${ }^{7}$ Division of Respiratory Therapy, The Children's Hospital of Philadelphia, Philadelphia, Pennsylvania; ${ }^{8}$ Institut de Ciències Fotòniques, Barcelona, Spain; ${ }^{9}$ Division of Cardiothoracic Surgery, The Children's Hospital of Philadelphia, Philadelphia, Pennsylvania; ${ }^{10}$ Department of Biostatistics and Epidemiology, University of Pennsylvania, Philadelphia, Pennsylvania; ${ }^{11}$ Department of Radiology, Hospital of the University of Pennsylvania, Philadelphia, Pennsylvania. Correspondence: Erin M. Buckley (buckley@nmr.mgh.harvard.edu) 
Table 1. Summary of patient recruitment

\begin{tabular}{|c|c|c|c|c|}
\hline & Pre-Norwood & Pre-Glenn & Pre-Fontan & Total \\
\hline Approached & 41 & \multicolumn{2}{|c|}{264} & 305 \\
\hline Consented & 27 & 35 & 71 & 133 \\
\hline $\begin{array}{l}\text { Studied with } \\
\text { DOS/DCS }\end{array}$ & 25 & 24 & 42 & 91 \\
\hline Given $\mathrm{NaHCO}_{3}$ & 8 & 8 & 6 & 22 \\
\hline \multicolumn{5}{|c|}{$\begin{array}{l}\text { Of the } 91 \text { patients monitored with DOS/DCS, } 22 \text { received an intravenous bolus of } \\
\mathrm{NaHCO}_{3} \text {. }\end{array}$} \\
\hline
\end{tabular}

Table 2. Patient characteristics

\begin{tabular}{llcc}
\hline Variable & Level & $\begin{array}{c}\mathrm{NaHCO}_{3} \\
\text { treated }\end{array}$ & Control \\
\hline Sex, $n(\%)$ & Male & $14(64)$ & $12(55)$ \\
& Female & $8(36)$ & $10(45)$ \\
Age $(\mathrm{y})$ & - & $0.5(0,1.8)$ & $0.4(0,1.7)$ \\
Weight $(\mathrm{kg})$ & - & $6.2(3.4,11.0)$ & $5.6(3.3,8.9)$ \\
Cardiac physiology, $n(\%)$ & Pre-stage I & $8(36.4)$ & $8(36.4)$ \\
& Pre-stage II & $8(36.4)$ & $8(36.4)$ \\
& Pre-stage III & $6(27.3)$ & $6(27.3)$ \\
\hline
\end{tabular}

Median (interquartile range) patient characteristics for both $\mathrm{NaHCO}_{3}$-treated and age-matched control patients. Patients were monitored on the day of staged cardiac surgical reconstruction, before surgery.

$\mathrm{NaHCO}_{3}$, sodium bicarbonate.

Table 3. Baseline systemic hemodynamics

\begin{tabular}{llcc}
\hline \multicolumn{1}{c}{ Variable } & $\mathrm{NaHCO}_{3}$ treated & Control \\
\hline Vital signs & Heart rate $(\mathrm{bpm})$ & $138(120,147)$ & $121(108,135)$ \\
& $\mathrm{MAP}(\mathrm{mm} \mathrm{Hg})$ & $64(61,68)$ & $63(56,71)$ \\
Arterial & $\mathrm{SpO}_{2}(\%)$ & $83(77,92)$ & $78(75,89)$ \\
blood gas & $\mathrm{pH}$ & $7.35(7.32,7.38)^{*}$ & $7.39(7.37,7.41)$ \\
& Arterial CO & $5.2(4.7,5.7)$ & $5.3(5.1,5.7)$ \\
& tension $(\mathrm{kPa})$ & & \\
& Arterial $\mathrm{O}_{2}$ & $6.7(6.3,7.9)$ & $6.5(5.7,7.6)$ \\
& tension $(\mathrm{kPa})$ & & $24(22,26)$ \\
& Bicarbonate $(\mathrm{mmol} / \mathrm{l})$ & $21(20,22)^{*}$ & $14.3(12.6,15.3)$ \\
& Hemoglobin $(\mathrm{g} / \mathrm{dl})$ & $14.3(12.6,15.6)$ & $-1(-3,+1)$ \\
& Base deficit $(\mathrm{mEq} / \mathrm{l})$ & $-4(-6,-3)^{* *}$ & 0 \\
& $\begin{array}{l}\text { Dosage NaHCO} \\
\text { (mEq/kg) }\end{array}$ & $0.8(0.6,0.9)$ & \\
\hline
\end{tabular}

Median (interquartile range) baseline vital signs and measures from arterial blood gas samples taken before administration of sodium bicarbonate in the treated group as well as age-matched controls $(n=22)$. A Wilcoxon signed-rank test was carried out to test for differences in each group as compared with the controls.

$\mathrm{MAP}$, mean arterial pressure; $\mathrm{NaHCO}_{3^{\prime}}$ sodium bicarbonate; $\mathrm{SpO}_{2^{\prime}}$, transcutaneous oxygen saturation.

${ }^{*} P<0.05,{ }^{* *} P<0.001$

CBF measurement, and the time frame for assessing the cerebral hemodynamic effects following drug administration.

The current observational pilot investigation aimed to quantify the immediate cerebral hemodynamic effects of a rapid (10-20 s) bolus administration of $\mathrm{NaHCO}_{3}$. Pilot data were taken $1-15 \mathrm{~min}$ after the bolus injection and were obtained from a subset of preoperative patients with hypoplastic left heart syndrome (HLHS) who were treated for mild acidemia during part of a larger presurgical brain imaging study. Noninvasive diffuse optical spectroscopies, namely, diffuse optical spectroscopy (DOS) and diffuse correlation spectroscopy (DCS), were used for $15 \mathrm{~min}$ postinjection to monitor regional changes in cerebral oxy- and deoxyhemoglobin concentrations $\left(\Delta \mathrm{HbO}_{2}\right.$ and $\Delta \mathrm{Hb}$, respectively), changes in total hemoglobin concentration $(\Delta \mathrm{THC})$, and changes in $\mathrm{CBF}$ relative to baseline $(\triangle \mathrm{rCBF})$ before rapid $\mathrm{NaHCO}_{3}$ administration.

\section{RESULTS}

As seen in Table 1, 305 patients were approached for this investigation; parental consent was obtained in 133, and 91 were studied with DOS/DCS. Of the 91 patients with HLHS monitored with DOS/DCS, 22 received $\mathrm{NaHCO}_{3}$ treatment for a mild or moderate base deficit: $n=8$ pre-Norwood, $n=8$ pre-Glenn, and $n=6$ pre-Fontan. Furthermore, we selected 22 age- and gender-matched control patients from the remaining 69 patients. These patients received no interventions but were monitored with DOS/DCS as part of the presurgical brain magnetic resonance imaging study. Patient characteristics for the treated and control groups are summarized in Table 2. $\mathrm{NaHCO}_{3}$-treated patients were mostly of male gender (64\%) and ranged in age from $1 \mathrm{~d}$ to $4 \mathrm{y}$.

Arterial blood gas data obtained before the administration of $\mathrm{NaHCO}_{3}$ are summarized in Table 3 for patients in the treated and control groups. Patients received a median (interquartile range) dose of $1.1(0.9,1.8) \mathrm{mEq} / \mathrm{kg} \mathrm{NaHCO}$ to treat a median (interquartile range) base deficit of $-4(-6,-3)$ $\mathrm{mEq} / \mathrm{l}$. Of note, the majority of patients were normocapnic but mildly hypoxemic with median (interquartile range) arterial oxygen tension of $6.3(8.0,6.7) \mathrm{kPa}$. The below-normal partial pressures of oxygen were expected due to the presence of intracardiac shunting, a consequence of single-ventricle physiology. Furthermore, arterial blood samples were not drawn after $\mathrm{NaHCO}_{3}$ administration; thus, changes in the parameters listed in Table 3 due to $\mathrm{NaHCO}_{3}$ are not reported. Baseline heart rate (HR), mean arterial pressure (MAP), and transcutaneous oxygen saturation $\left(\mathrm{SpO}_{2}\right)$ are also reported in Table 3 for both treated and control groups. No differences in these baseline parameters between treated and age-matched controls were observed.

Figure 1 provides box plots of $\Delta \mathrm{Hb}, \Delta \mathrm{HbO}_{2}, \Delta \mathrm{THC}$, and $\triangle \mathrm{rCBF}$ over time for the control and treated groups following the injection of intravenous $\mathrm{NaHCO}_{3}$. As compared with age-matched controls, patients showed significant increases in $\triangle \mathrm{rCBF}$ at $1 \mathrm{~min}$ after $\mathrm{NaHCO}_{3}$ injection $(P=0.0084)$. No significant changes in DOS measures of $\Delta \mathrm{Hb}, \Delta \mathrm{HbO}_{2}$, or $\Delta \mathrm{THC}$ were observed, nor were any significant differences in these parameters between the treatment group and the control group observed at any time following the injection. In addition, MAP, $\mathrm{HR}$, and $\mathrm{SpO}_{2}$ did not change following the administration of 
a

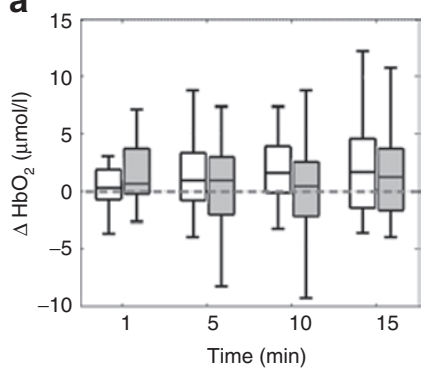

b

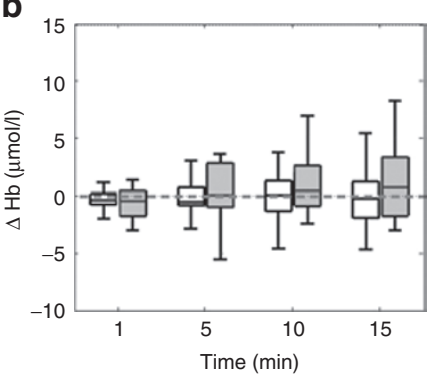

C

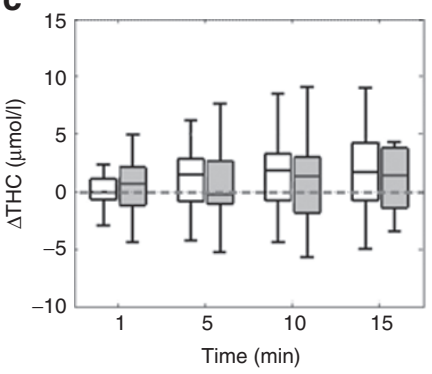

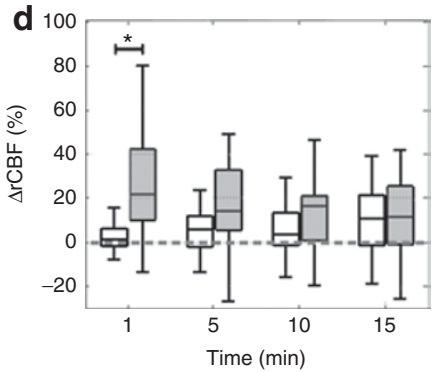

Figure 1. Box plots of changes from baseline in (a) oxy-, (b) deoxy-, and (c) total hemoglobin concentrations $\left(\Delta \mathrm{Hb}, \Delta \mathrm{HbO}_{2^{\prime}}\right.$ and $\Delta \mathrm{THC}$, respectively) and (d) relative cerebral blood flow $(\triangle \mathrm{rCBF})$ at times $1,5,10$, and $15 \mathrm{~min}$ following $\mathrm{NaHCO}_{3}$ administration (gray). The control group, which received no intervention, is shown in white. The dotted gray lines indicate no change from baseline levels. ${ }^{*} P<0.05 . \mathrm{NaHCO}_{3^{\prime}}$ sodium bicarbonate.
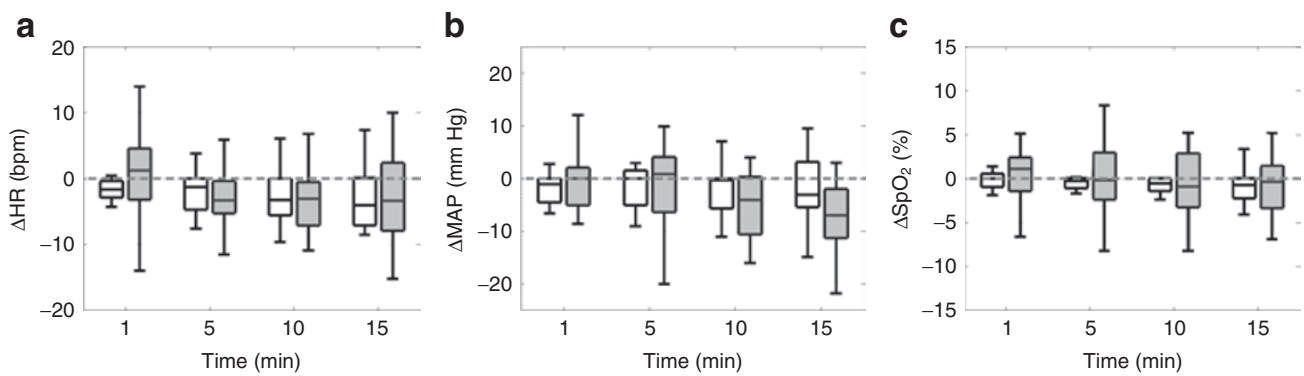

Figure 2. Box plots of changes from baseline in (a) heart rate, (b) mean arterial pressure, and (c) transcutaneous oxygen saturation at times 1, 5,10 , and 15 min following $\mathrm{NaHCO}_{3}$ administration (gray). The control group, which received no intervention, is shown in white. The dotted gray lines indicate no change from baseline levels. $\mathrm{NaHCO}_{3^{\prime}}$, odium bicarbonate.

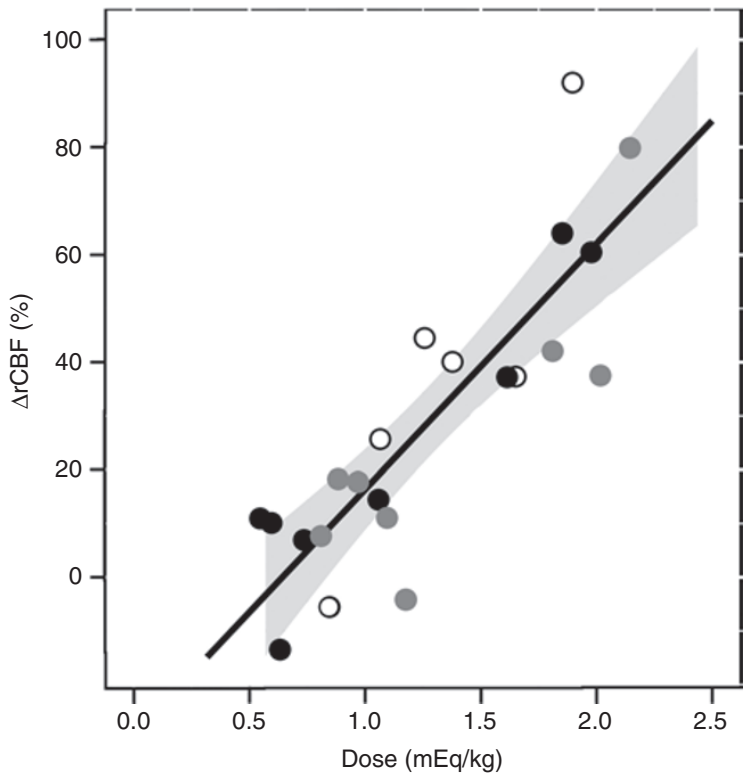

Figure 3. Relationship between the dose of sodium bicarbonate administered (in $\mathrm{mEq} / \mathrm{kg}$ ) and the associated change in cerebral blood flow (\%) $1 \mathrm{~min}$ after injection. The black line indicates the best linear fit to the data, and the $95 \%$ confidence interval to the fit is shown in the gray shaded region. Open circles denote pre-Fontan patients, black circles denote preGlenn patients, and gray circles denote pre-Norwood patients.

$\mathrm{NaHCO}_{3}$ in the treated patients as compared with controls (Figure 2).

In the $\mathrm{NaHCO}_{3}$-treated group, at 1 min postinjection, the increase in $\triangle \mathrm{rCBF}$ was highly correlated with $\mathrm{NaHCO}_{3}$ dosage $\left(R^{2}=0.71 ; P=2.1 \times 10^{6}\right.$; slope $(95 \%$ confidence interval $)=45.7(32.5,58.9) \% / \mathrm{mEq} / \mathrm{kg}$; Figure 3$)$. No relationship between change in $\triangle \mathrm{rCBF}$ at $1 \mathrm{~min}$ postinjection and baseline $\mathrm{pH}, \mathrm{PCO}_{2}$, or $\mathrm{PO}_{2}$ was observed (all $P>0.1$ ). The relationship between $\triangle \mathrm{rCBF}$ and $\mathrm{NaHCO}_{3}$ dosage weakened slightly by 5 min postinjection $\left(R^{2}=0.51 ; P=6.0 \mathrm{e}-4\right)$ and was no longer highly significant by $10 \mathrm{~min}$ after $\mathrm{NaHCO}_{3}$ administration (at $10 \mathrm{~min}, R^{2}=0.12 ; P=0.085$, and at $15 \mathrm{~min}, R^{2}=0.23 ; P=$ 0.042). Furthermore, no relationship was observed between cardiac physiology, age, weight, or arterial hemoglobin concentration and the change in $\triangle \mathrm{Hb}, \Delta \mathrm{HbO}_{2}, \Delta \mathrm{THC}$, or $\triangle \mathrm{rCBF}$ at any time point.

\section{DISCUSSION}

In this pilot observational study, we quantified the cerebral hemodynamic effects of $\mathrm{NaHCO}_{3}$ administered rapidly to treat metabolic acidemia in paralyzed, mechanically ventilated children with single-ventricle physiology. DCS demonstrated significant increases in CBF immediately (within $2 \mathrm{~min}$ ) following bolus administration of $\mathrm{NaHCO}_{3}$. These increases in $\mathrm{CBF}$ were strongly associated with the dosage of the $\mathrm{NaHCO}_{3}$, increasing in a linear fashion. This relationship between $\mathrm{CBF}$ and $\mathrm{NaHCO}_{3}$ dose was observed within all stages of HLHS cardiac physiology studied herein. The current investigation is the first to describe a dose-dependent response of $\mathrm{CBF}$ to $\mathrm{NaHCO}_{3}$. Population-averaged changes in oxy- or deoxyhemoglobin concentrations were not significantly different between the control and the treated groups. Quantification of the changes in cerebral hemodynamics that occur as a consequence of 
bolus injection of $\mathrm{NaHCO}_{3}$ may have a significant and beneficial impact on the treatment of metabolic acidemia in patients with congenital heart disease, especially in patients with bidirectional Glenn, in which pulmonary blood flow is dependent on CBF.

Although these data were obtained on mechanically ventilated patients with single-ventricle physiology, these results may be generalized to a larger pediatric population. Understanding the cerebral hemodynamic effects of $\mathrm{NaHCO}_{3}$ administration may be especially important in vulnerable populations such as premature infants, patients with impaired autoregulation from hypoxic-ischemic injury, or patients with focal or global cerebral edema for which the risk of rapid fluctuations in CBF does not outweigh the benefit of treating metabolic acidemia.

The mechanisms that govern the cerebral hemodynamic responses to a rapid $\mathrm{NaHCO}_{3}$ infusion are complex and not fully understood. Potentially, the observed increase in $\mathrm{CBF}$ was caused by an increase in the concentration of $\mathrm{CO}_{2}$, produced as a by-product of the reaction of $\mathrm{NaHCO}_{3}$ with acid, leading to an intracellular acidosis $(8,9)$. Although we did not obtain post- $\mathrm{NaHCO}_{3}$ administration arterial blood gas measurements, previous work suggests that $\mathrm{NaHCO}_{3}$ causes significant increases in the partial pressure of arterial $\mathrm{CO}_{2}$ in mechanically ventilated patients (20). $\mathrm{CO}_{2}$ is a potent vasodilator that induces increases in CBF through local effects on cerebral vasculature. Because our population was paralyzed under general anesthesia, the normal mechanism of responding to elevated arterial $\mathrm{CO}_{2}$ tension by increasing minute ventilation was eliminated. Therefore, it is possible that a more potent effect from $\mathrm{NaHCO}_{3}$ may have been observed in our population as compared with patients who are awake and spontaneously breathing.

Relatedly, the increase in CBF may reflect the increase in plasma osmolality following infusion. Siegel et al. (13) demonstrated an increase in osmolality and a decrease in hematocrit in critically ill neonates following the treatment of metabolic acidemia with $\mathrm{NaHCO}_{3}$. Both increased osmolality and decreased hematocrit have been linked to an increase in $\mathrm{CBF}$ via vasodilation and decreased viscosity, respectively (21). Therefore, in addition to the vasodilatory effects of $\mathrm{CO}_{2}$, hyperosmolality and/or a drop in hematocrit could be responsible for our observed increase in CBF.

Of note, we did not observe significant population-averaged changes in oxy-, deoxy-, or total hemoglobin concentrations. Vasodilation caused by $\mathrm{CO}_{2}$ and/or hyperosmolality following $\mathrm{NaHCO}_{3}$ administration might be expected to lead to increases in oxy- and total hemoglobin concentrations, as well as a slight decrease in deoxyhemoglobin concentration. However, a decrease in hematocrit after $\mathrm{NaHCO}_{3}$ (as shown in ref. 13) would likely be accompanied by a drop in oxy- and total hemoglobin concentrations, as well as an increase in deoxyhemoglobin concentration (22). Possibly, these two phenomena (i.e., vasodilation and a concomitatant drop in hematocrit) have opposite effects on tissue hemoglobin concentrations, leading to a population-averaged effect of no net change (i.e., within the error bars of our measured concentration changes).
Little work has been published on the cerebral effects of $\mathrm{NaHCO}_{3}$ to treat metabolic acidemia in human pediatric populations, and to our knowledge, only one publication has investigated the effects in patients with single-ventricle physiology (14). Overall, our results are consistent with several reports of the cerebral hemodynamic effects of $\mathrm{NaHCO}_{3}$ used to correct metabolic acidemia, although we did observe some disparities with other reports. van Alfen-van der Velden et al. (11) used continuous-wave near-infrared spectroscopy and transcranial Doppler ultrasound to study 15 preterm infants with metabolic acidosis treated with bolus administration of $\mathrm{NaHCO}_{3}$. Their cohort presented with more severe acidemia than our cohort, i.e., a base deficit less than $-6 \mathrm{mmol} / \mathrm{l}$ and $\mathrm{pH}<7.3$, and moreover, their cohort received half the dose $(\mathrm{mEq} / \mathrm{kg})$ of $\mathrm{NaHCO}_{3}$ than our population. As with our results, van Alfenvan der Velden et al. did not observe substantial changes in total hemoglobin concentration at 5 and $15 \mathrm{~min}$ post- $\mathrm{NaHCO}_{3}$ (they report changes in cerebral blood volume). By contrast to our findings, however, they also did not observe a significant change in CBF as measured by blood flow velocity in the internal carotid artery. This discrepancy may be due to the fact that Doppler ultrasound measures macrovascular changes in arterial flow velocity, whereas DCS measures microvascular flow directly in cortical tissue, and these two quantities may be disparate. Alternatively, the discrepancy may arise from the differences in age and physiology between the populations, or from the fact that 9 of 15 patients in their study (11) were spontaneously ventilating, thus permitting the patient to increase their minute ventilation to exhale the extra $\mathrm{CO}_{2}$ produced by $\mathrm{NaHCO}_{3}$.

Lou et al. (17) used the Xe-133 clearance technique to measure $\mathrm{CBF}$ changes $5 \mathrm{~min}$ after $\mathrm{NaHCO}_{3}$ injection in seven asphyxiated neonates with respiratory distress and acidosis (base deficit less than $-8 \mathrm{mEq} / \mathrm{l}$ ). Of note, they found profound decreases in global CBF in these infants, contrary to our findings, despite the fact that they administered the same base deficit-dependent dose per kilogram of $\mathrm{NaHCO}_{3}$. It is not clear why these results are contradictory; however, a possible explanation could be the difference in patient population. Unlike our otherwise healthy population with palliated congenital heart disease, their cohort was younger, i.e., preterm neonates, and their cohort had suffered asphyxia and potential damage to the blood-brain barrier. Therefore, bicarbonate ions, which are normally nonpermeable ions, may have been able to penetrate from the plasma to the extracellular fluid, leading to cerebrovasoconstriction and hence decreased CBF.

Bradley et al. (14) monitored 14 patients following bidrectional superior cavopulmonary connections with transcranial Doppler ultrasound of the middle or anterior cerebral artery. Unlike our study, these patients were not acidemic at baseline, i.e., population-averaged baseline $\mathrm{pH}=7.39$. However, the authors also observed a significant increase in CBF velocity for up to $15 \mathrm{~min}$ after a $4 \mathrm{mEq} / \mathrm{kg} \mathrm{NaHCO}$ bolus administration, similar to the findings observed in our patients. In addition, they observed an increase in systemic arterial saturations 
following bicarbonate administration, contrary to the findings in our bidirectional Glenn population.

In summary, a handful of publications that investigated the cerebral effects of $\mathrm{NaHCO}_{3}$ reported findings consistent with the ones presented herein. The discrepancies that do arise may reflect the severity and cause of the acidemia, the dosage and injection rate of $\mathrm{NaHCO}_{3}$, the use of mechanical ventilation, the differences in patient population, the anesthetic state, the method of CBF measurement, and the time frame for assessing the cerebral hemodynamic effects following drug administration.

\section{Study Limitations}

The results presented herein have several limitations. First, we did not draw a post- $\mathrm{NaHCO}_{3}$ arterial blood gas measurement because this was merely an observational pilot study. The current clinical practice at The Children's Hospital of Philadelphia following $\mathrm{NaHCO}_{3}$ administration is to not draw another arterial blood sample to confirm increases in $\mathrm{pH}, \mathrm{CO}_{2}$ tension, and bicarbonate ion concentration. Therefore, although we suggest that arterial $\mathrm{CO}_{2}$ levels increased following $\mathrm{NaHCO}_{3}$ administration due to the abundance of literature suggesting this effect $(9,10,15,20)$ and due to the observed dose-dependent increases in CBF, we cannot definitively confirm that $\mathrm{CO}_{2}$ increased in our cohort. Furthermore, we did not measure baseline albumin concentration, an important nonbicarbonate buffer that may also influence $\mathrm{CO}_{2}$ release following $\mathrm{NaHCO}_{3}$ injection and thus may affect subsequent cerebral hemodynamic changes $(20,23)$.

Second, we tracked changes in cerebral and systemic hemodynamics for only $15 \mathrm{~min}$ following $\mathrm{NaHCO}_{3}$ administration. Despite this limited monitoring time period, by $15 \mathrm{~min}$ postinjection, CBF was no longer significantly elevated. Therefore, we believe a 15-min window was sufficient to capture the rapid and transient effects of $\mathrm{NaHCO}_{3}$. In addition, we were limited to studying the effects of rapid infusion of $\mathrm{NaHCO}_{3}$. Future work will investigate variation of the infusion time in order to compare the potential beneficial effects of rapid vs. slow infusions.

Third, diffuse optical spectroscopies probe tissues located at shallow depths in the frontal cortex in the region under the optical probe. Although we presume that our frontal cortex measurements are indicative of whole-brain response to $\mathrm{NaHCO}_{3}$, absolute quantification of cerebral hemodynamics in other regions of the brain is beyond the scope of this work.

\section{Conclusions}

$\mathrm{NaHCO}_{3}$ is a commonly used medication administered for rapid correction of metabolic acidemia in adult, pediatric, and neonatal intensive care units. In pediatric patients with HLHS, we observed substantial increases in CBF following bolus intravenous $\mathrm{NaHCO}_{3}$ administration. These changes in $\mathrm{CBF}$ were linearly related to the dose of $\mathrm{NaHCO}_{3}$. On average, cerebral oxy- and deoxyhemoglobin concentrations did not change with $\mathrm{NaHCO}_{3}$ administration. Future work will benefit from the investigation of the effects of infusion rate on the $\mathrm{CBF}$ response to $\mathrm{NaHCO}_{3}$.

\section{METHODS}

\section{Study Protocol}

Infants and children with HLHS at various stages of palliation were enrolled, and parental consent was obtained for a presurgical brain magnetic resonance imaging and hypercapnia study (described in refs. $24,25)$ approved by the institutional review board at The Children's Hospital of Philadelphia. After induction of general anesthesia with paralysis in the operating room, patients were tracheally intubated. The anesthetic consisted of sevoflurane in room air for patients older than $3 \mathrm{mo}$ and fentanyl $(5 \mu \mathrm{g} / \mathrm{kg})$ for neonates. Supplemental oxygen was not utilized. Patients were mechanically ventilated using a tidal volume to achieve an arterial $\mathrm{CO}_{2}$ of $4.93-5.60 \mathrm{kPa}$. An arterial catheter was placed in the umbilical artery in pre-Norwood patients and in an ulnar or radial artery in pre-Glenn and pre-Fontan patients. Patients were then transferred to the magnetic resonance imaging table, and a noninvasive optical probe (see description below) was placed on the forehead for continuous $(0.2 \mathrm{~Hz})$ optical monitoring of cerebral hemodynamics. HR via electrocardiogram and peripheral hemoglobin-oxygen saturation $\left(\mathrm{SpO}_{2}\right)$ via pulse oximetry were monitored and continuously recorded at a rate of $0.5 \mathrm{~Hz}$ throughout the duration of the study. Noninvasive (cuff) MAP was measured every 3 min.

After the patient was stabilized, an arterial blood gas measurement was drawn. Blood gas analysis was performed using an i-STAT handheld blood analyzer (Abbott Laboratories, Princeton, NJ) to derive blood $\mathrm{pH}$, partial pressure of carbon dioxide and oxygen, base excess or base deficit, bicarbonate ion concentration, hemoglobin concentration, and hematocrit. As part of routine clinical care during the study, any calculated base deficit less than $-2 \mathrm{mEq} / \mathrm{l}$ was treated at the attending anesthesiologist's discretion (not protocolized) with bolus intravenous administration of $8.4 \% \mathrm{NaHCO}_{3}$ over a $10-30$ s period. All patients in this study were hemodynamically stable, including those patients with a base deficit between -2 and -3 , for whom the decision to treat was solely based on the practitioner's preference. The acuity of the patient's illness did not play a role in the decision to treat. The following formula was used to calculate the $\mathrm{NaHCO}_{3}$ dosage: patient weight $(\mathrm{kg}) \times 1 / 3(\mathrm{l} / \mathrm{kg}) \times$ base deficit $(\mathrm{mEq} / \mathrm{l})$. If $\mathrm{NaHCO}_{3}$ was given, a second blood gas measurement was not obtained following $\mathrm{NaHCO}_{3}$ administration.

\section{Cerebral Monitoring}

A hybrid diffuse optical instrument combining DOS and DCS was used to noninvasively monitor cerebral hemodynamics. This instrument has been described previously (24), and the techniques and theoretical analysis have been described at length (26). Briefly, DOS uses three near-infrared wavelengths, 688,787 , and $826 \mathrm{~nm}$, and uses a modified Beer-Lambert law (22) to quantify changes in tissue oxy- and deoxyhemoglobin concentrations, $\Delta \mathrm{HbO}_{2}$ and $\Delta \mathrm{Hb}$, respectively, in the region of brain approximately $1-1.5 \mathrm{~cm}$ under the optical probe, i.e., in the cortex surface region. The sum of these changes gives variation of total hemoglobin concentration $\left(\Delta \mathrm{THC}=\Delta \mathrm{Hb}+\Delta \mathrm{HbO}_{2}\right)$, a quantity that is generally assumed to be proportional to the change in cerebral blood volume. DCS monitors temporal fluctuations of the reflected light intensity, specifically, the temporal intensity autocorrelation function of detected near-infrared light is computed using a semi-infinite homogeneous approximation in order to derive a blood flow index (26). Previous studies have shown that changes of blood flow index in various model systems agree with $\triangle \mathrm{rCBF}$ measured by other techniques (24-28). The sources and detectors for both DOS and DCS were separated by $2.5 \mathrm{~cm}$ and held in place by a black rubber probe.

\section{Data Analysis}

To quantify the effects of $\mathrm{NaHCO}_{3}$ on hemodynamics, a 1-min mean of each of the following parameters was obtained immediately before and at $1,5,10$, and $15 \mathrm{~min}$ after the injection of $\mathrm{NaHCO}_{3}: \Delta \mathrm{HbO}_{2}, \Delta \mathrm{Hb}$, $\triangle \mathrm{THC}, \triangle \mathrm{rCBF}, \triangle \mathrm{HR}, \triangle \mathrm{MAP}$, and $\Delta \mathrm{SpO}_{2}$. These time intervals were chosen because the effects of $\mathrm{NaHCO}_{3}$ were expected to be clearly evident due to the rapid onset and transient action of $\mathrm{NaHCO}_{3}$. Changes in each $\mathrm{DOS}$ parameter, i.e., $\mathrm{Hb}, \mathrm{HbO}_{2}$, and $\mathrm{THC}$, and vital sign parameter, i.e., $\mathrm{HR}, \mathrm{MAP}$, and $\mathrm{SpO}_{2}$, were quantified as the difference between a 1 -min average taken $1,5,10$, and $15 \mathrm{~min}$ after $\mathrm{NaHCO}_{3}$ injection and 
a 1-min average immediately before the injection. Relative changes in DCS-measured CBF were quantified using the following formula:

$$
\Delta \mathrm{rCBF}=\left(\left(\frac{\langle\text { blood flow index }\rangle_{\text {post }}}{\langle\text { blood flow index }\rangle_{\text {pre }}}\right)-1\right) \times 100 \%
$$

Here, the angle brackets indicate the mean taken over a 1-min time period, and the subscripts pre and post denote means taken before and after $\mathrm{NaHCO}_{3}$ injection, respectively. Note that the four post averages were quantified at the time points specified above.

A subset of patients who did not receive $\mathrm{NaHCO}_{3}$ treatment were used as controls. These control patients were individually matched with each $\mathrm{NaHCO}_{3}$-treated patient for both age (within $4 \mathrm{mo}$ ) and cardiac physiology. Vital sign and DOS/DCS monitoring were acquired continuously for these patients, although they received no intervention. These control patients were intended to elucidate the normal physiologic variations that occur during the monitoring period. The baseline period for these patients was the first minute of DOS/DCS data acquisition, and changes in DOS, DCS, and vital sign parameters were computed in the same manner as described above at 1, 5, 10, and 15 min after the baseline.

\section{Statistical Analyses}

A Wilcoxon signed-rank test was carried out to test whether the $\mathrm{NaHCO}_{3}$-treated group showed significantly different changes in vital signs and cerebral hemodynamics as compared with age- and physiology-matched controls. Furthermore, to quantify the relationship between the dosage of $\mathrm{NaHCO}_{3}$ and the subsequent change in CBF measured with DCS, we fit a simple linear regression model; using this model, we estimated the Pearson's correlation coefficient. The Pearson's correlation coefficient, $R$, varies from 0 to 1.0 and measures the extent to which a linear model explains variability in the data. Analyses were performed using R 2.11 statistical software (R Foundation for Statistical Computing, Vienna, Austria). Hypotheses tests and associated $P$ values were two sided. A Hochberg correction was used to adjust the $P$ values for multiple comparisons. Statistical significance was declared for $P$ values $<0.05$.

\section{ACKNOWLEDGMENTS}

We thank David Busch, Justine Wilson, Heather Chandler, the Cardiac Anesthesia staff, the respiratory therapists, and most important, the patients and their families for their participation.

\section{STATEMENT OF FINANCIAL SUPPORT}

This work was supported by the National Institutes of Health at the University of Pennsylvania (NS-060653, PI: A.G.Y.) and at The Children's Hospital of Philadelphia (grant HL090615, PI: M.A.F.; grant NS072338, PI: D.J.L.; grant NS-052380, PI: D.J.L.; grant T32AL07915, PI: D.A.G.; grant T32NS007413, PI: E.M.B.); by the National Center for Research Resources and the National Institute of Biomedical Imaging and Bioengineering of the National Institutes of Health through grant P41-EB015893; by the Dana Foundation; and by the Steve and Judy Wolfson Family Trust.

Disclosure: The authors declared no conflict of interest.

\section{REFERENCES}

1. Aschner JL, Poland RL. Sodium bicarbonate: basically useless therapy. Pediatrics 2008;122:831-5.

2. Berg CS, Barnette AR, Myers BJ, Shimony MK, Barton AW, Inder TE. Sodium bicarbonate administration and outcome in preterm infants. J Pediatr 2010;157:684-7.

3. Corbet AJ, Adams JM, Kenny JD, Kennedy J, Rudolph AJ. Controlled trial of bicarbonate therapy in high-risk premature newborn infants. J Pediatr 1977;91:771-6.

4. Sabatini S, Kurtzman NA. Bicarbonate therapy in severe metabolic acidosis. J Am Soc Nephrol 2009;20:692-5.

5. Papile LA, Burstein J, Burstein R, Koffler H, Koops B. Relationship of intravenous sodium bicarbonate infusions and cerebral intraventricular hemorrhage. J Pediatr 1978;93:834-6.

6. Simmons MA, Adcock EW 3rd, Bard H, Battaglia FC. Hypernatremia and intracranial hemorrhage in neonates. N Engl J Med 1974;291:6-10.
7. Laptook AR. The effects of sodium bicarbonate on brain blood flow and $\mathrm{O} 2$ delivery during hypoxemia and acidemia in the piglet. Pediatr Res 1985;19:815-9.

8. Ostrea EM Jr, Odell GB. The influence of bicarbonate administration on blood pH in a "closed system": clinical implications. J Pediatr 1972;80:67180.

9. Nakashima K, Yamashita T, Kashiwagi S, Nakayama N, Kitahara T, Ito H. The effect of sodium bicarbonate on $\mathrm{CBF}$ and intracellular $\mathrm{pH}$ in man: stable Xe-CT and 31P-MRS. Acta Neurol Scand, Supplc 1996;166:96-8.

10. Singer RB, Deering RC, Clark JK. The acute effects in man of a rapid intravenous infusion of hypertonic sodium bicarbonate solution. II. Changes in respiration and output of carbon dioxide. J Clin Invest 1956;35:245-53.

11. van Alfen-van der Velden AA, Hopman JC, Klaessens JH, Feuth T, Sengers RC, Liem KD. Effects of rapid versus slow infusion of sodium bicarbonate on cerebral hemodynamics and oxygenation in preterm infants. Biol Neonate 2006;90:122-7.

12. Kravath RE, Aharon AS, Abal G, Finberg L. Clinically significant physiologic changes from rapidly administered hypertonic solutions: acute osmol poisoning. Pediatrics 1970;46:266-75.

13. Siegel SR, Phelps DL, Leake RD, Oh W. The effects of rapid infusion of hypertonic sodium bicarbonate in infants with respiratory distress. Pediatrics 1973;51:651-4.

14. Bradley SM, Simsic JM, Mulvihill DM. Hypoventilation improves oxygenation after bidirectional superior cavopulmonary connection. J Thorac Cardiovasc Surg 2003;126:1033-9.

15. Fanconi S, Burger R, Ghelfi D, Uehlinger J, Arbenz U. Hemodynamic effects of sodium bicarbonate in critically ill neonates. Intensive Care Med 1993;19:65-9.

16. Huseby JS, Gumprecht DG. Hemodynamic effects of rapid bolus hypertonic sodium bicarbonate. Chest 1981;79:552-4.

17. Lou HC, Lassen NA, Fris-Hansen B. Decreased cerebral blood flow after administration of sodium bicarbonate in the distressed newborn infant. Acta Neurol Scand 1978;57:239-47.

18. Tibballs J. Bicarbonate and haemodynamics in neonates. Intensive Care Med 1993;19:63-4.

19. Young RS, Yagel SK, Woods CL. The effects of sodium bicarbonate on brain blood flow, brain water content, and blood-brain barrier in the neonatal dog. Acta Neuropathol 1984;65:124-7.

20. Levraut J, Garcia P, Giunti C, et al. The increase in $\mathrm{CO} 2$ production induced by $\mathrm{NaHCO} 3$ depends on blood albumin and hemoglobin concentrations. Intensive Care Med 2000;26:558-64.

21. Younkin DP, Reivich M, Jaggi JL, Obrist WD, Delivoria-Papadopoulos M. The effect of hematocrit and systolic blood pressure on cerebral blood flow in newborn infants. J Cereb Blood Flow Metab 1987;7:295-9.

22. Lee J, Cerussi AE, Saltzman D, Waddington T, Tromberg BJ, Brenner M. Hemoglobin measurement patterns during noninvasive diffuse optical spectroscopy monitoring of hypovolemic shock and fluid replacement. J Biomed Opt 2007;12:024001.

23. Okamoto H, Hoka S, Kawasaki T, Okuyama T, Takahashi S. Changes in end-tidal carbon dioxide tension following sodium bicarbonate administration: correlation with cardiac output and haemoglobin concentration. Acta Anaesthesiol Scand 1995;39:79-84.

24. Buckley EM, Hance D, Pawlowski T, et al. Validation of diffuse correlation spectroscopic measurement of cerebral blood flow using phaseencoded velocity mapping magnetic resonance imaging. J Biomed Opt 2012;17:037007.

25. Durduran T, Zhou C, Buckley EM, et al. Optical measurement of cerebral hemodynamics and oxygen metabolism in neonates with congenital heart defects. J Biomed Opt 2010;15:037004.

26. Durduran T, Choe R, Baker WB, Yodh AG. Diffuse optics for tissue monitoring and tomography. Rep Prog Phys 2010;73:1-43.

27. Kim MN, Durduran T, Frangos S, et al. Noninvasive measurement of cerebral blood flow and blood oxygenation using near-infrared and diffuse correlation spectroscopies in critically brain-injured adults. Neurocrit Care 2010;12:173-80.

28. Zhou C, Eucker SA, Durduran T, et al. Diffuse optical monitoring of hemodynamic changes in piglet brain with closed head injury. J Biomed Opt 2009;14:034015. 